\title{
PERBEDAAN PERAN JENIS KELAMIN, SKALA AKADEMIK, DAN PERAN AKTIF BERORGANISASI DENGAN PRESTASI AKADEMIK
}

\author{
Nuryati Atamimi \\ Fakultas Psikologi Universitas Gadjah Mada \\ email: atamiminuryati@gmail.com
}

\begin{abstract}
Abstrak: Penelitian bertujuan menyusun inventori kepribadian (IKP-2) lanjutan, dimensi perbedaan peran jenis kelamin dan skala akademik bermuara dari Inventory for Counseling and Development (ICD) serta hubungannya dengan peran aktif berorganisasi dan prestasi akademik. Subjeknya 200 mahasiswa Fakultas Psikologi UGM angkatan 2008 s.d. 2011. Pengumpulan data menggunakan skala IKP-2, dengan jawaban sesuai keyakinan yang paling menggambarkan diri sendiri. Prestasi akademik adalah Indeks prestasi kumulatif. Analisis menggunakan ANAVA satu jalur. Hasil penelitian menunjukkan bahwa IKP-2 berkorelasi positif signifikan dengan indeks prestasi, perbedaan peran jenis kelamin dan peran aktif berorganisasi. Tetapi, aspek performansi akademik, keunggulan akademik, kemampuan akademik, dan motivasi akademik tidak berkorelasi dengan IPK dan peran aktif berorganisasi.
\end{abstract}

Kata Kunci: skala kepribadian IKP-2, skala kepribadian ICD, sex role differences, peran aktif berorganisasi, prestasi akademik

\section{SEX ROLE DIFFERENCES, ACADEMIC SCALES AND THE ACTIVE ROLES IN AN ORGANIZATION ON ACADEMIC ACHIEVEMENT}

\begin{abstract}
The study was aimed to develop an advanced personality inventory (IKP-2), with the dimensions of sex role differences and Academic scales based on the Counseling and Development Inventory (ICD), and its relationship with the active roles ofan organization and the academic achievement. As many as 200 students of the Faculty of Psychology UGM 2008 s/d 2011 were chosen as the subjects of this study. The data were collected using the advanced personality inventory (IKP-2) with the responses based on the belief closely representing the students them selves. The data were analyzed by utilizing the one way ANAVA. The findings showed that IKP-2 had a positive and significant correlation with academic achievement, sex role differences, and the active roles in an organization. However, there was no correlation between IKP-2 and the active roles in an organization on the one hand, and the academic performance, academic excellence, academic capacity, and academic motivation.
\end{abstract}

\section{Keywords: IKP-2 personality scale, ICD personality scale, sex role differences, active roles in an organization, academic achievement}

\section{PENDAHULUAN}

Instrumen pengukuran psikologis IKP merupakan inventori kepribadian yang digunakan untuk kepentingan konseling dan pengembangan. Namun demikian, tercakup pula unsur pengukuran untuk menentukan kemampuan intelektual, bakat, minat, dan kepribadian dalam penjurusan di sekolah. Instrumen itu juga digunakan sebagai alat bantu untuk menentukan diagnosis kegagalan akademis dan seleksi siswa baru maupun untuk evaluasi serta perencanaan pendidikan dan karier individu.
Instrumen pengukuran psikologis yang mampu memberikan diagnosis dan prediksi secara tepat tampaknya masih belum sesuai dengan kebutuhan. Hal ini terlihat dari terbatasnya jumlah dan jenis instrumen pengukuran psikologis yang tersedia di Indonesia. Sering pula dijumpai instrumen pengukuran psikologis dari luar negeri yang bukan berbahasa Indonesia dan diperlukan untuk keperluan diagnosis serta prediksi, tetapi belum dapat dipakai karena materinya sangat dipengaruhi oleh budaya asing. 
Penggunaan tes dari luar negeri perlu dilakukan adaptasi karena pembuatan suatu tes didasarkan pada sampel dan latar belakang budaya penyusun tes sehingga apabila langsung diterapkan pada pemakai tes kemungkinan akan dipersepsikan secara berbeda pula (Cronbach, 1970). Oleh karena itu, tes psikologi yang berasal dari luar negeri haruslah disesuaikan dengan kondisi masyarakat di negeri ini. Salah satu aspek yang berperan dalam kehidupan manusia adalah aspek kepribadian. Untuk mengungkap kepribadian perlu adanya suatu instrumen pengukuran kepribadian baku yang benarbenar dapat mengungkap kepribadian.

Dengan mempertimbangkan hal-hal di atas, dipandang perlu dilakukan penyusunan suatu inventori kepribadian yang bermuara dari konstruk teoretis bentuk aslinya yang berasal dari Amerika untuk keperluan di Indonesia. Tes kepribadian bentuk asli mengacu pada Inventory for Counseling and Development (ICD) yang disusun oleh Giddan, Crecch, dan Lovell (1988). Langkah berikutnya setelah penelitian ini adalah upaya uji kelayakan instrument, yaitu inventori pengukuran kepribadian IKP untuk mengukur validitas, reliabilitas, besaran daya beda item, dan menyusun norma yang baku. Penelitian semacam ini lebih dikenal dengan istilah standardisasi agar dapat dimanfaatkan sebagai alat bantu dalam aktivitas konseling dan psikoterapi, pengajaran, perencanaan pendidikan, penelusuran dan pengembangan karier mahasiswa, serta menambah dan melengkapi khasanah inventori alat ukur kepribadian di Fakultas Psikologi Universitas Gadjah Mada.

Salah satu tujuan dari proses belajar mengajar adalah adanya perubahan tingkah laku baik aspek pengetahuan, sikap, dan psikomotorik. Salah satu perubahan aspek kognitif mahasiswa dapat dilihat dari indeks prestasi yang diperoleh. Indeks prestasi dijadikan sebagai tolok ukur penguasaan akademik. Semakin baik penguasaan akademik mahasiswa maka prestasi yang diperoleh pun akan baik pula.

Azwar (2004) mengemukakan bahwa secara umum ada dua faktor yang memengaruhi prestasi akademik seseorang, yaitu faktor internal dan faktor eksternal. Faktor internal melipu- ti antara lain faktor fisik dan faktor psikologis. Faktor fisik berkaitan dengan kondisi fisik umum seperti penglihatan dan pendengaran. Faktor psikologis menyangkut faktor-faktor non fisik, seperti minat, motivasi, bakat, intelegensi, sikap dan kesehatan mental. Faktor eksternal meliputi faktor fisik dan faktor sosial. Faktor fisik menyangkut kondisi tempat belajar, sarana dan perlengkapan belajar, materi pelajaran, kondisi lingkungan belajar dan lingkungan alam. Faktor sosial menyangkut dukungan sosial dan pengaruh budaya. Peran aktif berorganisasi merupakan faktor sosial yang turut berpengaruh terhadap prestasi akademik mahasiswa karena seorang mahasiswa juga harus membutuhkan kecerdasan emosional yang menjadikan mahasiswa kreatif dalam mengelola waktu untuk belajar dan berorganisasi (Nurgianto, 2008). Temuan penelitian tentang peran aktif berorganisasi terhadap partisipasi kegiatan OSIS berpengaruh positif terhadap kreativitas belajar dengan korelasi sebesar 0,474 dan kontribusi sebesar 22.4\% (Hermawan, 2013). Nurlitasari (2010) mengemukakan hasil penelitiannya bahwa terdapat perbedaan prestasi akademik antara mahasiswa yang sangat aktif, aktif, kurang aktif, dan tidak aktif berorganisasi.

Dalam dunia pendidikan formal, pentingnya pengukuran prestasi akademik tidak dapat disangsikan lagi. Sebagaimana diketahui, proses pendidikan formal adalah suatu proses kompleks yang memerlukan waktu, dana, dan usaha serta kerja sama dari berbagai pihak. Berbagai aspek dan faktor terlibat dalam proses pendidikan secara keseluruhan. Tidak ada pendidikan berhasil mencapai tujuan yang digariskan tanpa interaksi berbagai faktor pendukung yang ada dalam sistem pendidikan tersebut. Betapapun jelasnya suatu tujuan pendidikan telah digariskan, tanpa usaha pengukuran, maka akan mustahil hasilnya dapat diketahui. Tidaklah layak untuk menyatakan suatu kemajuan atau keberhasilan program pendidikan tanpa memberikan bukti peningkatan atau pencapaian yang diperoleh. Bukti peningkatan atau pencapaian inilah yang merupakan tujuan pengukuran prestasi secara terencana. 
Zahroh (2008) dalam penelitiannya menemukan bahwa ada pengaruh langsung peran gender terhadap prestasi belajar siswa SMK PGRI Turen Malang dengan signifikansi sebesar 0,001 . Siswa perempuan lebih banyak yang berprestasi dari pada siswa laki-laki. Siswa perempuan cenderung memunyai kepribadian rapi dalam belajar, motivasi untuk belajar lebih tinggi, sedangkan siswa laki-laki cenderung agak malas belajar, bersikap acuh terhadap motivasi belajar. Namun, dalam hal tantangan kesuksesan akademik siswa laki-laki lebih tinggi, sedangkan perempuan lebih bersifat aktif belajar karena pengaruh kondisi setempat yang membentuk agar rajin belajar.

Berdasarkan beberapa hasil penelitian, ditemukan bahwa sex role differences belum menentukan prestasi akdemik, sedangkan academic scale dapat menentukan prestasi akademik. Selanjutnya, peran aktif dalam berorganisasi turut membantu dalam meningkatkan prestasi akademik. Oleh karena itu, perlu diteliti kembali korelasi antara perbedaan peran gender tehadap prestasi akademik sehingga para pemerhati psikologi dapat memberikan konseling dengan tepat untuk meningkatkan prestasi akademik siswa. Dua skala ini yaitu sex role differences dan academic scale, termasuk dalam instrumen pengukuran kepribadian inventori untuk konseling dan pengembangan (IKP-2) dimensi criterion scale yang merupakan inventori kepribadian yang digunakan untuk kepentingan konseling dan pengembangan.

Langkah dalam pembuatan skala: Identifikasi pembuatan alat ukur penetapan konstruk psikologis $\rightarrow$ operasionalisasi konsep indikator perilaku $\rightarrow$ penskalaan dan pemilihan format stimulus $\rightarrow$ penulisan item reviu item $\rightarrow$ uji coba $\rightarrow$ analisisi item $\rightarrow$ kompilasi i seleksi item $\rightarrow$ pengujian realibilitas $\rightarrow$ validasi $\rightarrow$ kompilasi ii format final. Penelitian ini baru mencakup kompilasi I seleksi dan kelayakan item.

Berdasarkan berbagai definisi mengenai kepribadian ada empat persamaan yang menjadi ciri. Pertama, kepribadian bersifat umum, menunjuk kepada sifat umum seseorang, pikiran, kegiatan dan perasaan yang berpengaruh secara sistemik terhadap keseluruhan tingkah lakunya.
Kedua, kepribadian bersifat khas, untuk menjelaskan sifat individu yang membedakan dia dengan orang lain. Ketiga, kepribadian berjangka lama, untuk menggambarkan sifat individu yang awet, tidak mudah berubah sepanjang hayat, kalau terjadi perubahan biasanya bertahap atau akibat respon sesuatu kejadian. Keempat, kepribadian bersifat kesatuan, diri sebagai unit tunggal, struktur atau organisasi internal hipotetik yang membentuk kesatuan dan konsisten dan yang terakhir kepribadian berfungsi baik atau buruk, adalah bagaimana orang berada di dunia. Apakah tampil dalam tampilan yang baik, kepribadian yang sehat dan kuat Atau tampil dengan kepribadian menyimpang atau lemah.

Brown (1981) mengemukakan bahwa ada tiga metode untuk mengukur kepribadian. Ketiga metode itu adalah (1) self report inventory; (2) teknik proyeksi; dan (3) situational test. Dalam metode self report inventory penguji memberikan sejumlah pernyataan atau pertanyaan yang mendiskripsikan tingkah laku subjek. Asumsi yang dibuat dalam metode ini adalah bahwa subjek yang dites adalah orang yang paling mengerti, paling tahu akan keadaannya sendiri, dan tingkah lakunya sendiri. Selain itu, subjek yang dites memunyai kesediaan dan kemampuan untuk menyatakan keadaannya dan melaporkan tingkah lakunya menurut apa adanya (Suryabrata, 1979).

ICD merupakan jenis skala kepribadian yang digunakan untuk mengukur secara objektif beberapa skala kepribadian dan secara khusus digunakan untuk mengungkap performance academic seseorang atas dasar profile kepribadiannya. Aplikasi ICD adalah pada bidangbidang pendidikan terutama di universitas untuk program konseling, seleksi mahasiswa baru, perencanaan pendidikan dan karier, proses belajar, evaluasi pengajaran, dan penelitian. Oleh karena itu, ICD pada umumnya dikenakan pada individu dengan tingkat perkembangan antara masa remaja akhir sampai masa dewasa awal.

Jumlah butir ICD sebanyak 449 buah yang terbagi menjadi 23 skala dan dikelompokan menjadi tiga skala utama, yaitu (1) validity scale yang mengungkap seperangkat respon 
individu seperti inconsistency, tendensi ke arah penipuan serta pola-pola respon yang khas; (2) substantive scale yang mengungkap fungsi kepribadian dalam berbagai bidang; (3) criterion scale yang mengungkap komponen kepribadian dan motivasional yang berkaitan dengan perilaku akademik. Konsep yang digunakan di dalam ICD, diasumsikan bahwa perilaku siswa dan mahasiswa terjadi dalam kaitannya dengan variasi kepribadian, motivasi dan kepercayaan. Ada tiga paradigma psikologi yang digunakan di dalam pengembangan ICD, yaitu psychodinamic clinical paradigm, cognitive social learning paradigm, dan developmental paradigm.

Criterion scale, di dalam skala ini terdapat skala perbedaan peranan jenis kelamin dan skala akademik untuk masing-masing jenis kelamin. Skala ini mengukur komponen-komponen kepribadian dan motivasional yang berkaitan dengan perilaku akademik. Rincian skala penelitian IKP-2 lanjutan ini adalah sex role differences dan academic scale

Skala perbedaan peran jenis kelamin (sex role differences scale) mengukur ada kecenderungan respon menurut pandangan pria dan wanita terhadap hal-hal yang menyangkut masalah personal, sosial, dan minat. Aspek ini dirancang dengan menyusun 20 butir. Academic scale terdiri atas empat skala yang mengukur komponen kepribadian dan motivasional yang berkaitan dengan perilaku akademik. Aspek ini masih terbagi lagi menjadi 4 sub aspek, yaitu academic performance scale, academic exellent scale, academic capacity scale, dan academic motivation scale masing-masing dengan 20 butir pertanyaan.

Peran aktif berorganisasi adalah seseorang yang ikut berpartisipasi, terlibat dalam pengambilan keputusan, terlibat dalam memberikan dampak kemajuan atau produktivitas organisasi. Peran aktif berorganisasi dapat berbentuk loyalitas dan komitmen untuk terlibat pada kegiatan atau program organisasi.

Penelitian ini ingin mengetahui seberapa tinggi hubungan antara Skala IKP-2 dimensi criterion scale dengan prestasi akademik mahasiswa.

\section{METODE}

Subjek penelitian adalah mMahasiswa Fakultas Psikologi UGM angkatan tahun 2008 sampai dengan tahun 2011 sejumlah 295 orang yang terdiri atas 157 mahasiswa laki-laki dan 138 mahasiswa perempuan. Meskipun faktor inteligensi sangat menentukan prestasi akademik, untuk penelitian ini tidak diukur dengan anggapan bahwa seleksi calon mahasiswa yang ketat sehingga layak diterima di Fakultas Psikologi UGM tentu mahasiswa yang minimal memunyai IQ rata-rata. Variabel bebas adalah sex role differences, academic scale, dan Peran aktif berorganisasi, sedang variabel terikat adalah prestasi akademik.

Sex role differences dan academic scale diungkap sebagai skor skala IKP-2 dimensi criterion scale dan sex role differnces scale, sedangkan untuk aspek academic scale secara operasional diungkap sebagai skor skala IKP-2 dimensi criterion scale sub-academic scale. Peran aktif berorganisasi adalah pengalaman mahasiswa didalam struktur kepengurusan organisasi dan berperan aktif mengikuti organisasi yang diukur melalui angket tingkatan keterlibatan dalam berorganisasi. Prestasi akademik merupakan nilai yang diperoleh peserta didik dalam pembelajaran. Ukuran prestasi akademik mahasiswa yang digunakan dalam penelitian ini adalah nilai Indeks Prestasi Kumulatif (IPK) yang diperoleh melalui dokumentasi bagian pengajaran Fakultas Psikologi Universitas Gadjah Mada.

Penyusunan item untuk skala IKP-2 telah dibuat lebih sederhana dirancang untuk dapat disesuaikan dengan kondisi dan budaya masyarakat Indonesia. Prosedur penyusunan skala tetap mengacu kepada konstruk teoretis ketika menyusun skala ICD namun dengan item yang baru bukan hanya melakukan adaptasi. Skala IKP-2 untuk penelitian ini sengaja hanya menyentuh dimensi criterion yang melibatkan 2 aspek. Adapun 2 aspek di dalam sriterion scale tersebut mengelompok menjadi lima kategori sub aspek yaitu sex role differences, academic performance scale, academic exellent scale, academic capacity scale, academic motivation scale. Dari 5 aspek ini disusun masing-masing 
20 item ditambah 10 item yang sama untuk kepentingan konsistensi jawaban responden. Dengan demikian, secara keseluruhan ada 110 item. Skala IKP-2 yang akan disusun terdiri dari 110 item berupa pernyataan favourable dan unfavourable. Pilihan jawaban sesuai dengan keyakinan diri, yaitu memilih angka 1 berarti memang merasa tidak sesuai dengan pernyataan tersebut dengan kenyataan yang ada pada diri sendiri. Angka 2 berarti sedikit agak sesuai dan demikian seterusnya menurut perkiraan mahasiswa sampai angka 5 yang berarti pernyataan tersebut sangat sesuai dengan kenyataan yang ada pada diri sendiri. Pilihan yang paling sesuai menggambarkan tentang diri sendiri. Skala diberikan kepada subjek penelitian untuk diisi berdasarkan gambaran dirinya sendiri.

Prosedur skoring yang digunakan untuk penelitian ini adalah skoring secara manual. Pada prosedur skoring ini data entri seluruh responden dijumlahkan dan diambil rerata nilai pada setiap item. Item skala dianggap layak apabila rerata empirik di atas nilai rerata hipotetik (2.5), dan item dianggap kurang layak atau perlu diperbaiki lagi apabila rerata empirik di bawah nilai rerata hipotetik (Edwards, 1957). Hasil data item akan diketahui kelayakan skala dan perbaikan skala. Untuk mengetahui konsistensi jawaban subjek, dibuat soal yang sama persis dengan sebaran nomor item dan dipilih secara acak. Pada nomor item tertentu sebagai cek konsistensi jawaban, maka akan diketahui konsistensi respon subjek antara jawaban pada nomor sebelumnya dan jawaban pada nomor sesudahnya.
Penelitian ini belum menyentuh langkah untuk menguji validitas, reliabilitas, penyusunan norma dalam rangka standardisasi. Data yang didapatkan pada alat ukur IKP-2 yaitu berupa skoring secara manual. Pada prosedur scoring ini skala infrequent harus diskor terlebih dahulu. Apabila diperoleh t-skor 70 ke atas atau 30 ke bawah hasil tersebut dianggap tidak valid atau tidak bisa diskor kemudian digambarkan pada profil untuk jenis kelamin yang sesuai. Kemudian skor mentah dikonversikan ke dalam t-skor atau persentil. Uji statistik yang digunakan adalah ANOVA satu jalur.

\section{HASIL DAN PEMBAHASAN \\ Hasil}

Hasil uji statistik (interkorelasi) antarvariabel yang diteliti ditunjukkan pada Tabel 1. Hasil uji interkorelasi antara aspek-aspek pada skala IKP-2 menunjukkan bahwa sex role differences berkorelasi dengan academic exellent scale, academic capacity scale, dan academic motivation scale dengan masing-masing aspek menunjukkan nilai $\mathrm{p} ; 0.00<0.01$. Selanjutnya, pada aspek academic performance hanya menunjukkan nilai korelasi yang tinggi pada academic capacity scale dengan nilai p; 0.23. Pada aspek academic exellent scale menunjukkan ada korelasi dengan aspek sex role differences, academic capacity scale, academic motivation scale dengan menunjukkan angka korelasi yang cukup tinggi dengan p; 0.00. Aspek academic exellent scale belum berkorelasi terhadap aspek Academic performance karena hasil hitungan statistik menunjukkan p; 0.108.

Tabel 1: Hasil Uji Interkorelasi Aspek-Aspek IKP-2

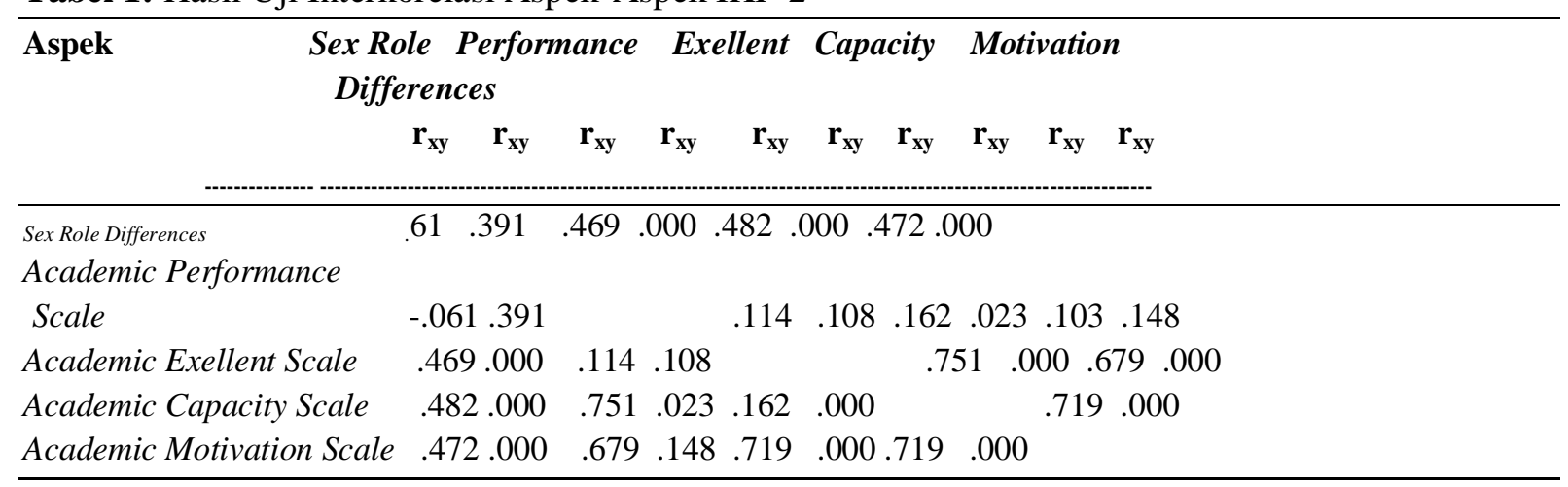


Aspek academic capacity scale memperlihatkan korelasi yang tinggi pada semua aspek. Korelasi academic capacity scale dengan academic performance menunjukkan nilai p; 0.23 , sedangkan Aspek academic capacity scale berkorelasi dengan aspek sex role differences, academic exellent scale, academic motivation scale dengan nilai $\mathrm{p} ; 0.00$.

Pada aspek academic motivation scale belum menunjukkan korelasi yang tinggi pada aspek academic performance, nilai korelasi tersebut menunjukkan nilai $\mathrm{p}$; 0.148 , namun, aspek academic motivation scale menunjukkan nilai korelasi yang tinggi pada aspek sex role differences, academic exellent scale, academic capacity scale dengan nilai p: 0.00 .

Dari hasil analisis uji Anava pada skala IKP-2 berdasarkan perbedaan jenis kelamin, memperlihatkan adanya perbedaan cara subjek merespon berdasarkan jenis kelamin yang ber- hubungan dengan personal, sosial dan minat pada sesuatu hal (p. 0.000). Pada mahasiswa perempuan memberikan respon dengan nilai yang lebih tinggi daripada mahasiswa laki-laki. Skala IKP-2 telah berkontribusi secara positif dalam memprediksi perbedaan pada minat dan akademi pendidikan ditinjau dari perbedaan jenis kelamin mahasiswa.

Selanjutnya, dilakukan uji korelasi terhadap nilai Indeks Prestasi Komulatif mahasiswa tanpa memandang perbedaan jenis kelamin, angka statistik menunjukkan nilai p: 0.011 . Skala IKP-2 telah bisa digunakan untuk melihat sikap personal terhadap academic dikaitkan dengan prediksi hasil akhir nilai IPK. Namun, bila ditinjau pada aspek-aspek Skala IKP-2, belum bisa menunjukkan korelasi yang diharapkan karena nilai p: 0.05. Hanya pada aspek Sex role differences menunjukkan korelasi yang tinggi pada skala IKP-2 dengan nilai p: 0.019 .

Tabel 2. Hasil Uji Perbedaan IKP-2 dengan Peran Jenis Kelamin

\begin{tabular}{|c|c|c|c|c|}
\hline Aspek & \multicolumn{2}{|c|}{$\mathbf{F}$} & $\mathbf{p}$ & Keterangan \\
\hline Sex role differences & \multicolumn{2}{|c|}{$218.652 \quad 0.000$} & Ada perbedaan respon & \\
\hline Academic performance scale & 11.209 & 0.002 & terhadap Skala IKP-2 & \\
\hline Academic exellent scale & 55.433 & 0.000 & $\begin{array}{l}\text { berdasarkan jenis } \\
\text { kelamin }\end{array}$ & \\
\hline Academic capacity scale & 48.099 & 0.000 & & \\
\hline Academic motivation scale & 50.230 & 0.000 & & \\
\hline IKP-2 & 121.619 & 0.000 & & \\
\hline
\end{tabular}

Tabel 3: Hasil Uji Korelasi IKP-2 dengan Index Prestasi Kumulatif (IPK)

\begin{tabular}{|c|c|c|c|}
\hline \multirow[t]{3}{*}{ Aspek } & \multicolumn{2}{|c|}{ Hasil uji } & \multirow[t]{2}{*}{ Keterangan } \\
\hline & $\mathbf{r}_{\mathrm{xy}}$ & $\mathbf{p}$ & \\
\hline & .167 & 0.019 & \multirow{7}{*}{$\begin{array}{l}\text { IKP-2 berkorelasi dengan Index Prestasi mahasiswa. } \\
\text { IKP-2 Berkorelasi dengan Sex role differences. } \\
\text { IKP-2 tidak berkorelasi dengan: Academic performance, } \\
\text { Academic exellent, Academic capacity, Academic moti- } \\
\text { vation }\end{array}$} \\
\hline Sex role differences & .105 & 0.142 & \\
\hline Academic performance scale & .049 & 0.494 & \\
\hline Academic exellent scale & .024 & 0.732 & \\
\hline Academic capacity scale & .100 & 0.163 & \\
\hline Academic motivation scale & .181 & 0.011 & \\
\hline IKP-2 & & & \\
\hline
\end{tabular}


Tabel 4. Hasil Uji Korelasi IKP-2 dengan Peran Aktif Mahasiswa dalam Berorganisasi

\begin{tabular}{lclll}
\hline \multicolumn{1}{c}{ Aspek } & $\mathbf{r}_{\mathbf{x y}}$ & $\mathbf{p}$ & Arti \\
\hline Sex role differences & -.219 & .002 & IKP-2 berkorelasi dengan peran aktif mahasiswa dalam \\
Academic performance scale & .076 & .289 & berorganisasi. \\
Academic exellent scale & -.049 & .494 & Pada aspek Sex role differences terdapat korelasi tes \\
Academic capacity scale & -.044 & .540 & IKP-2 pada peran aktif mahasiswa dalam berorganisasi. \\
Academic motivation scale & -.118 & .099 & Pada aspek Academic performance, Academic exellent \\
IKP-2 & -.162 & .022 & scale, Academic capacity scale, Academic motivation \\
& & & scale tidak berkorelasi pada peran aktif mahasiswa \\
& & &
\end{tabular}

Hasil temuan Skala IKP-2 memunyai korelasi yang tinggi terhadap peran aktif mahasiswa dalam berorganisasi, hitungan statistik menunjukkan angka p; 0.022. Skala IKP-2 bisa digunakan untuk memprediksi perilaku akademik yang dihubungkan dengan keaktifan mahasiswa dalam berorganisasi. Akan tetapi bila ditinjau dari aspek-aspek Skala IKP-2 belum menunjukkan adanya korelasi dengan peran aktif mahasiswa dalam berorganisasi. Hanya pada aspek Sex role differences terdapat korelasi skala IKP-2 dengan peran aktif mahasiswa dalam berorganisasi, hitungan statistik menunjukkan angka p; 0.002 .

\section{Pembahasan}

Skala IKP-2 terdiri atas lima aspek, yaitu sex role differences, academic performance scale, academic exellent scale, academic capacity scale, academic motivation scale. Hasil uji menjunjukkan ada perbedaan respon skala IKP2 berdasarkan jenis kelamin. Skala IKP-2 menunjukkan ada korelasi dengan index prestasi dan peran aktif dalam berorganisasi. Akan tetapi, bila dikorelasikan dengan aspek-aspek skala IKP-2, hasilnya belum menunjukkan adanya korelasi pada index prestasi dan peran aktif mahasiswa dalam berorganisasi. Hanya pada aspek sex role differences menunjukkan ada korelasi terhadap index prestasi dan peran aktif dalam berorganisasi.

Berdasarkan penghitungan statistik interkorelasi antara aspek-aspek pada skala IKP-2 menunjukkan bahwa sex role differences berkorelasi dengan academic exellent scale, academic capacity scale, dan academic motivation scale. Selanjutnya, pada aspek academic performance hanya menunjukkan nilai korelasi yang tinggi pada academic capacity scale dan pada aspek academic exellent scale menunjukkan ada korelasi dengan aspek sex role differences, academic capacity scale, academic motivation. Aspek academic exellent scale belum berkorelasi terhadap aspek academic performance. Aspek academic capacity scale memperlihatkan korelasi yang tinggi pada semua aspek. Pada aspek academic motivation scale menunjukkan korelasi yang tinggi pada aspek sex role differences, academic exellent, academic capacity, academic performance, aspek academic motivation.Akan tetapi pada aspek academic performance belum menunjukkan korelasi terhadap dengan academic motivation. Aspek-aspek pada skala IKP-2 bisa saling berkorelasi kecuali pada aspek performance scale yang hanya berkorelasi dengan academic capacity scale. Hal ini menunjukkan perlunya perbaikan item pada aspek tersebut agar bisa saling berkorelasi dengan aspek yang lainnya untuk membentuk skala IKP-2 secara utuh.

Uji beda di setiap item dalam aspek guna mengetahui konsistensi antara fungsi item dengan fungsi skala dari jawaban yang dianggap sesuai terhadap kriteria perilaku yang diukur, menunjukkan bahwa dari 100 item, baru 20 item yang memenuhi persyaratan memunyai fungsi selaras dengan tujuan pengukuran skala.

Nunnally (1981) menyatakan bahwa untuk menentukan jumlah subjek dalam uji coba alat ukur hendaklah diperhatikan jumlah itemnya. Banyaknya subjek untuk sampel sebaiknya berjumlah enam kali lipat hingga sepuluh kali 
lipat dari jumlah item. Bila digunkan pada skala IKP-2 yang berjumlah 100 item, maka jumlah subjek idealnya antara 600 subjek hingga 1000 . Penentuan jumlah komunitas subjek juga turut mempengaruhi pada heterogenitas populasi, berkaitan dengan karakteristik populasi yang relevan untuk dipertimbangkan. Kurangnya jumlah subjek, nampak mempengaruhi jumlah item yang gugur setelah melihat nilai koefisien korelasi item-total yang menunjukan daya beda item, banyak item yang memunyai nilai kurang dari 0.25. Skala IKP-2 belum mengungkapkan perbedaan individual antara yang memiliki sifat yang diukur dan yang tidak memiliki sikap tersebut. Hal ini karena pengujian korelasi itemtotal menunjukkan homogenitas item dengan keseluruhan skala. Karena luasnya bidang yang diukur pada masing-masing aspek, sulit mendapatkan korelasi item-total yang tinggi.

Evaluasi penyusunan item yang pertama adalah perlunya penambahan peserta diskusi di dalam personal judgment yang membahas aksara bahasa untuk mengurangi dan menghilangkan adanya pernyataan yang mengandung social desirability. Pada pelaksanaan penelitian, peneliti meminta kepada responden untuk memberikan catatan pada pertanyaan dan jawaban yang dianggap pernyataan ambigue. Hasil ini menjadikan bahan perbaikan pada pembuatan item untuk penelitian selanjutnya.

Evaluasi yang kedua, penambahan subjek dengan memenuhi persyaratan enam sampai sepuluh kali lipat banyaknya item dalam menentukan jumlah subjek. Tahap yang kedua peneliti melakukan uji empiris secara kuantitatif kepada subjek dari mahasiswa Fakultas Psikologi semester 4-8. Secara metodologi, baru diambil subjek pada satu lokasi saja. Sebagai bahan evaluasi, harus diperhatikan banyaknya variasi karakteristik subjek pada beberapa lokasi agar mendapatkan populasi yang heterogen sehingga hasil akan lebih representatif dan dapat terdistribusi secara normal.

\section{PENUTUP}

Penelitian ini menghasilkan kesimpulan sebagai berikut. (1) Ada perbedaan respon terhadap Skala IKP-2 berdasarkan jenis kelamin.
(2) Skala IKP-2, criterion scale berkorelasi positif dan signifikan dengan Index Prestasi $k u$ mulatif, sex role differences dan peran aktif berorganisasi. (3) IKP-2 tidak berkorelasi signifikan dengan academic performance, academic exellent, academic capacity, academic motivation.

\section{UCAPAN TERIMA KASIH}

Penelitian ini tidak akan sampai pada kesimpulan akhir tanpa bantuan dari banyak pihak. Oleh karena itu, pada kesempatan ini peneliti ingin menyampaikan rasa terima kasih yang tak terhingga kepada: (1) Fakultas Psikologi UGM yang telah mendanai penelitian ini melalui Program Hibah Fakultas Psikologi; (2) mahasiswa Fakultas Psikologi angkatan tahun 2008- 2011 yang telah bersedia sebagai subyek penelitian; (3) Farida Aryati, S.Psi. yang mendampingi selama proses penelitian berlangsung dan Adelia Khrisna Putri, S.Psi. yang banyak berperan dalam proses penyempurnaan naskah hasil penelitian ini; (4) Jurnal Pendidikan Cakrawala Universitas Negeri Yogyakarta sebagai sponsor, khususnya Bapak Burhan Nurgiyantoro selaku Ketua Redaktur dan Sdr. Binar yang telah bersedia memuat naskah hasil penelitian ini sehingga sampai ketangan sidang pembaca. Semoga membawa manfaat bagi banyak kalangan.

\section{DAFTAR PUSTAKA}

Azwar, S. 2004. Tes prestasi: Fungsi Pengembangan Pengukuran Prestasi Belajar. Yogyakarta: Pustaka Pelajar.

Brown, F. G. 1981. Principles of Educational and Psychological Testing. New York: Holt Rinehart and Winston.

Cronbach, L. J. 1970. Essentials of Psychological Testing. New York: Harper \& Brothers Publishers.

Edwards, Allen L. 1957. Tecniques of Attitude Scale Countruction. Appleton Century Crafts. New York. 
Nguyen, N.T., Allen, L.C., Fraccastoro,K. 2005. "Personality Predicts Academic Performance: Exploring the Moderating Role of Gender". Journal of Higher Education Policy and Management. 571 (7).

Nunnally, J. 1981. Psychometric Theory. New Delhi: Tata Mc Graw Hill Publishing Company, Ltd.

Nurgiyanto, S.F. 2008. "Pengaruh Kekatifan Berorganisasi dan Minat Belajar terhadap Prestasi Akademik Mata Pelajaran Akuntansi di MAN 3 Malang". Tesis Program Pendidikan Akuntansi Jurusan Akuntansi Fakultas Ekonomi Universitas Negeri Malang.
Nurlitasari, Y. 2010. "Pengaruh Keaktifan Berorganisasi dan Motivasi Belajar Terhadap belajar siswa pada bidang Akuntansi Di SMAN 1 Blitar". Tesis Program Pendidikan Akuntansi Jurusan Akuntansi Fakultas Ekonomi Universitas Negeri Malang.

Suryabrata, S. 1979. "Pengukuran dalam Psikologi Kepribadian". Pidato Pengukuhan sebagai Guru Besar dalam Psikologi. Yogyakarta: Yayasan Penerbitan Psikologi Universitas Gadjah Mada.

Zahroh, F. 2008. "Pengaruh gender terhadap Motivasi Memilih Sekolah dan Prestasi Belajar Siswa di SMK PGRI Turen Malang”. Skripsi, Program Studi Pendidikan Matematika, Universitas Negeri Malang. 